\title{
Organocatalytic and Halide-Free Synthesis of Glycerol Carbonate under Continuous Flow
}

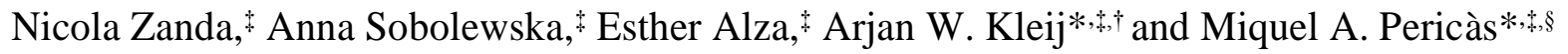

¥ Institute of Chemical Research of Catalonia (ICIQ), The Barcelona Institute for Science \& Technology (BIST), Av. Països Catalans 16, 43007 Tarragona, Spain;

$\dagger$ Catalan Institute of Research and Advanced Studies (ICREA), Pg. Lluis Companys 23, $08010-$ Barcelona (Spain); orcid.org/0000-0002-7402-4764;

Email: akleij@iciq.es

§ Departament de Química Inorgànica i Orgànica, Universitat de Barcelona, 08028 Barcelona, Spain; orcid.org/0000-0003-0195-8846;

Email: mapericas@iciq.es

SUPPORTING INFORMATION

26 pages, 16 figures, 5 tables, 1 Equation 


\section{Contents:}

Page S3:

Page S4:

Page S6:

Page S7:

Page S8:

Page S10:

Page S11:

Page S12:

Page S13:

Page S14:

Page S15:

Page S16:

Page S17:

Page S20-26:
General information

Experimental setup for the flow experiments

Catalyst stability test

Experimental flow protocol

Comparison between crude and purified glycerol carbonate

Example spectroscopic analysis of a fraction of the flow experiments

NMR analysis of the glycidol feed

Swelling tests performed for $\mathbf{1}$

Table S3

Comparison of fresh and used catalyst by IR analysis

Batch optimization experiments

Synthesis of precursors

Synthesis of heterogeneous catalysts

Copies of relevant NMR and IR spectra 


\section{General Information:}

Unless otherwise noted, all commercial reagents were used as received without further purification or drying, including $\mathrm{CO}_{2}$ which was purchased from PRAX-38 AIR. Flash chromatography was carried out using 60 mesh silica gel and dry-packed columns. Thin layer chromatography was carried out using Merck TLC silica gel 60 F254 aluminum sheets. Components were visualized by UV light $(\lambda=254 \mathrm{~nm})$ and stained with $\mathrm{KMnO}_{4}$. NMR spectra were recorded at $298 \mathrm{~K}$ on a Fourier $300 \mathrm{MHz}$ Bruker, a Bruker Avance 400 Ultrashield or a Bruker Avance 500 Ultrashield apparatus. Chemical shifts are reported in ppm relative to the residual solvent peaks in $\mathrm{CDCl}_{3}(\delta=7.26 \mathrm{ppm})$ or DMSO-d $\mathrm{d}_{6}(\delta=2.50 \mathrm{ppm})$. Elemental analyses were performed by MEDAC Ltd, United Kingdom. IR spectra were recorded on a Bruker Tensor 27 FT-IR spectrometer. 


\section{Experimental setup for the flow experiments:}

The feed of starting material, glycidol, dissolved in methylethyl ketone (MEK) was provided by a Knauer Azura P4.1 pump with integrated pressure sensor. The feed was flowed through a check-valve $(\mathrm{CV})$ into the tube-in-tube reactor (with a $0.6 \mathrm{~mL}$ inner tube volume), employed in the traditional configuration, where it is saturated in $\mathrm{CO}_{2}$ and passed through a second $\mathrm{CV}$ into a $1.0 \mathrm{~mL}$ pre-heating coil warmed to $70^{\circ} \mathrm{C}$ by an oil bath. The reactant stream was then passed through a third CV into the packed bed reactor (PBR) reactor employed in the up-flow configuration. We employed a Diba Omnifit ${ }^{\circledR}$ SolventPlus ${ }^{\mathrm{TM}}$ as PBR equipped with Chemraz O-rings resistant to the reaction media. The column was kept at the desired temperature through a jacketed glass reactor heated through an oil stream mediated by a Julabo oil heater. The jacketed glass reactor and all the tubing that were subjected to heating were insulated by glass wool, epoxy resin and aluminum tape. Finally, a back-pressure regulator (BPR) from IDEX was used to operate a "closed" system. A liquid stream was finally collected in an Erlenmeyer, following sampling for ${ }^{1} \mathrm{H}$ NMR spectroscopic analysis.
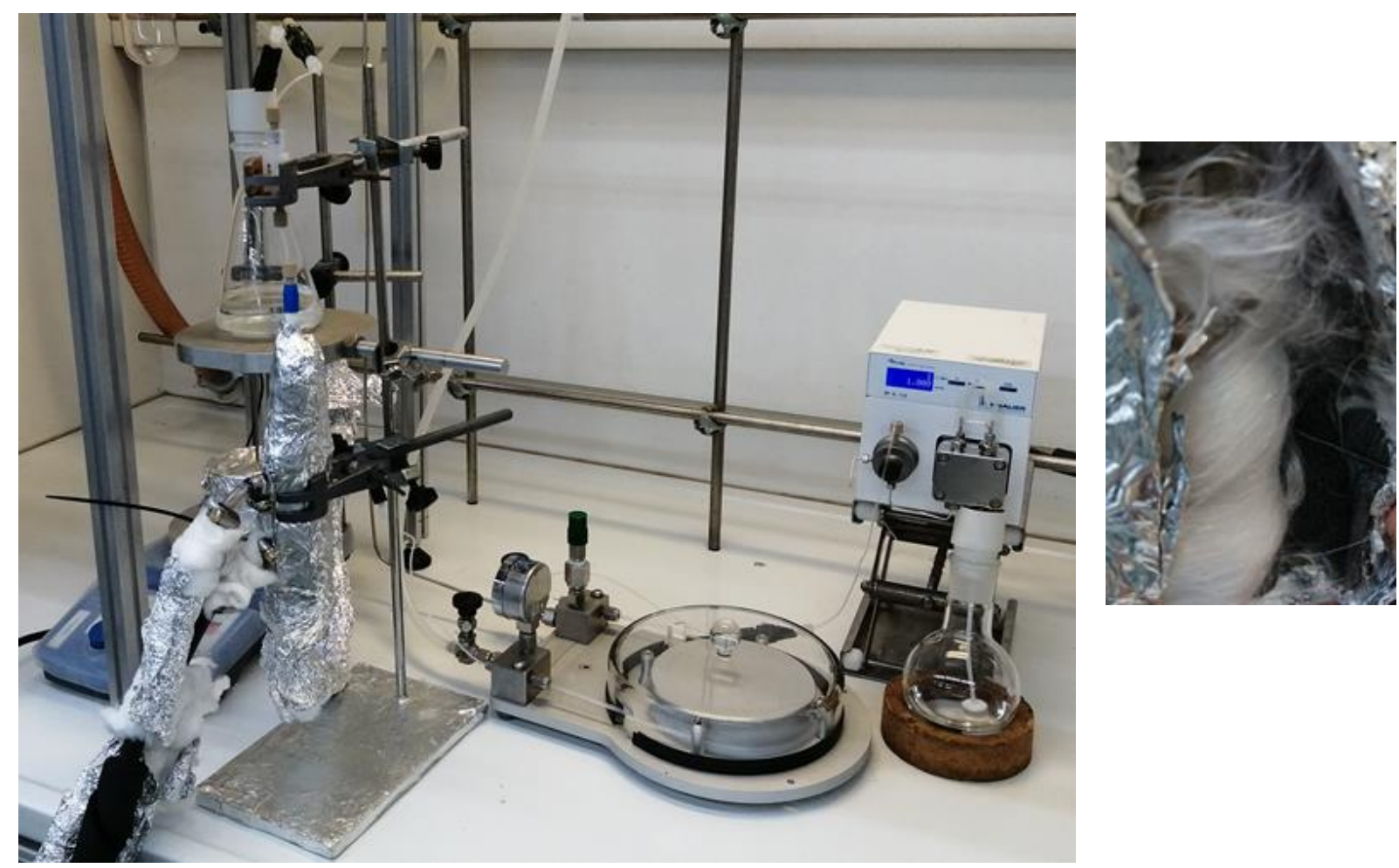

Figure S1: On the left a picture of the setup, on the right how the column is insulated from the external environment by wrapping it in glass wool and a poly-epoxy resin. 
Considerations about the flow setup:

The tube-in-tube reactor is a membrane reactor with a shell configuration. In the traditional configuration, which we employed, the liquid stream flows inside the inner tube and the gas is located in the outer space between the two tubes. The properties of the Teflon AF-2400 allows to saturate the stream with the desired gas in matter of seconds according to the providers. During all our experiments, the residence time (the time the feed was in contact with the reactor) was always in the order of minutes. The pressure of the $\mathrm{CO}_{2}$ applied in the inner tube was between 3 and 8 bar, with the total pressure of the system being around 17 bar. 


\section{Catalyst stability test:}

Swellable catalysts are exploited only when completed swollen, and therefore tests were performed to determine whether the pressure 'approximations' from Henry's law can be applied. When a catalyst is in the gel phase it can perform properly whereas when it loses it gel structure ( $c f$., drying), it indicates the loss of $\mathrm{CO}_{2}$ from the solution resulting into a biphasic flow (gas and liquid) operation. Therefore, we performed these experiments to assure that catalyst 1 was acting in a gel-phase and there was no out-gassing of $\mathrm{CO}_{2}$ while heating.

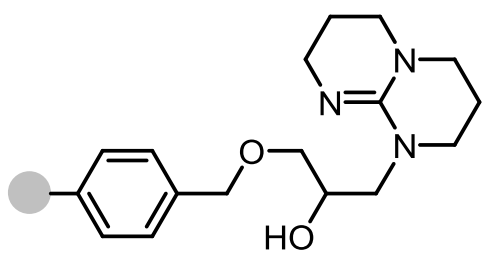

1. TBD@Merrifield

Table S1: Results of the physical stability test for catalyst $1 .^{a}$

\begin{tabular}{ccccc} 
Entry & $\begin{array}{c}\mathbf{T} \\
\left({ }^{\mathbf{o}} \mathbf{C}\right)\end{array}$ & $\begin{array}{c}\mathbf{C O}_{2} \text { in t-i-t } \\
(\mathbf{b a r})\end{array}$ & $\begin{array}{c}\text { BPR } \\
(\mathbf{b a r})\end{array}$ & PBR \\
\hline 1 & $\mathrm{rt}$ & 8 & 8 & gel \\
2 & 50 & 8 & 8 & dry \\
3 & 60 & 8 & 8 & dry \\
$4^{b}$ & 70 & - & 8 & gel \\
5 & $\mathrm{rt}$ & 8 & 17.24 & gel \\
6 & 60 & 8 & 17.24 & gel \\
7 & 70 & 8 & 17.24 & gel \\
$8^{c}$ & 70 & 3 & 13.40 & gel
\end{tabular}

${ }^{a}$ The PBR was equipped with $800 \mathrm{mg}$ of catalyst. The system was tested flowing MEK at 0.11 $\mathrm{mL} / \mathrm{min}, \tau 30 \mathrm{~min}$, at a constant pressure of $\mathrm{CO}_{2}$ of 8 bar in the tube-in-tube reactor. The system was operated for $4 \mathrm{~h}$ and checked. ${ }^{b}$ This experiment, in the absence of $\mathrm{CO}_{2}$, was performed to exclude that MEK was responsible for drying of the reactor. ${ }^{c}$ This experiment was performed as a test for the long-run flow catalysis. Since we decreased the pressure of $\mathrm{CO}_{2}$ down to $3 \mathrm{bar}$, it was possible to decrease the overall pressure of the system through a lower BPR which was based on the general trend of $\mathrm{CO}_{2}$ solubility in butanone based on the data reported by Gui. ${ }^{1}$

\footnotetext{
${ }^{1}$ X. Gui, Z. Tang, W. Fei, J. Chem. Eng. Data 2011, 56, 2420-2429, DOI: 10.1021/je101344v.
} 


\section{Experimental flow protocol:}

- The system is first primed with solvent and the catalyst is swollen

- The solvent is exchanged for the feed solution and flowed through the system

- When the feed arrives and fills the tube-in-tube reactor, the $\mathrm{CO}_{2}$ manometer is opened at the desired pressure. The tube-in-tube reactor is then primed three times with cycles opening and closing the gas exit. At the end the exit key is closed

- The heat exchanger is then turned on at the desired temperature

- When the feed solution is about to finish, the feed container is rinsed with solvent

- Finally, the system is cleaned with solvent 
Comparison between crude and purified glycerol carbonate:

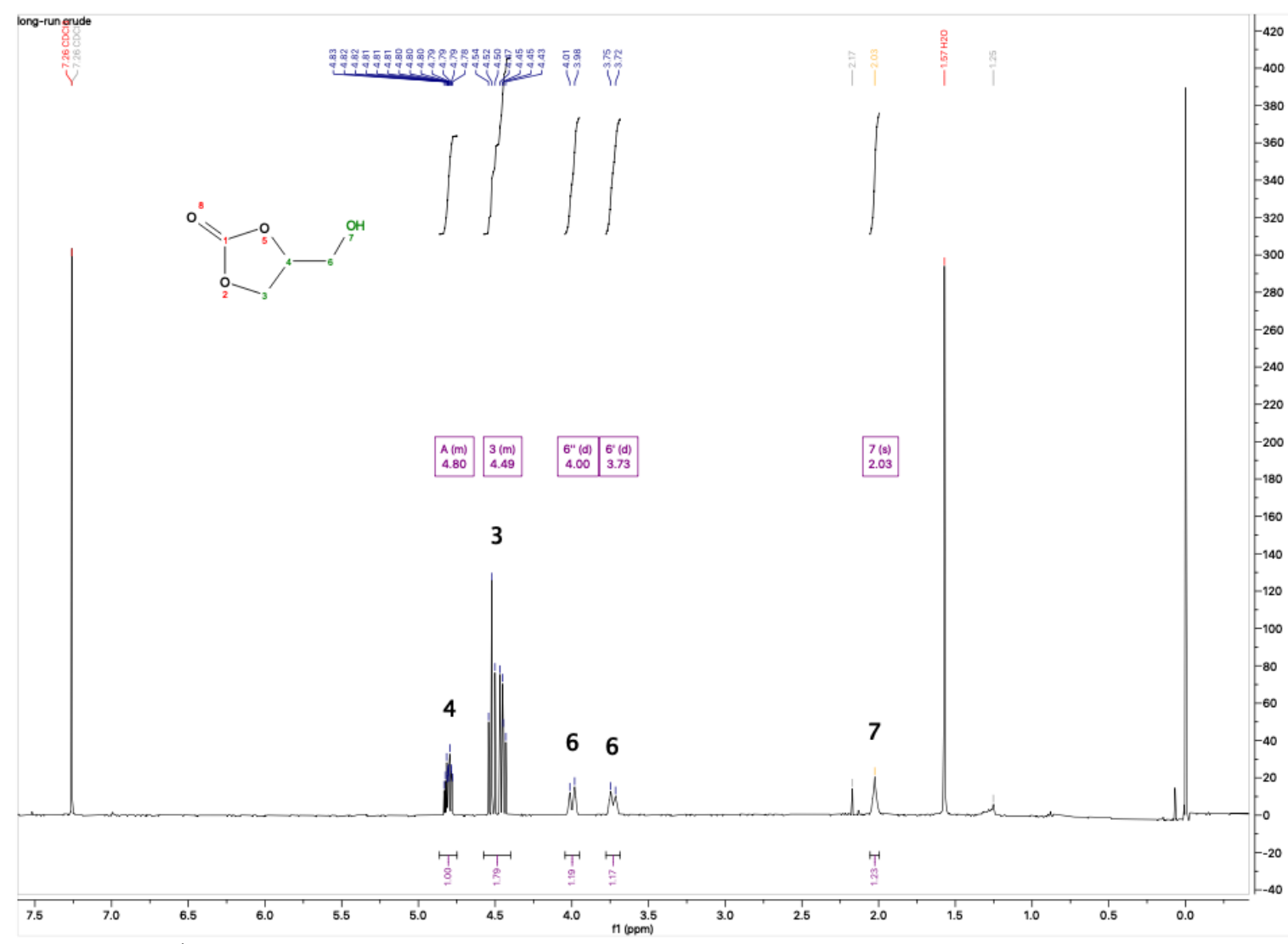

Figure S2: ${ }^{1} \mathrm{H}$ NMR spectrum $\left(\mathrm{CDCl}_{3}\right)$ of the crude product after the long-run experiment. $2.17 \mathrm{ppm}$ acetone traces, $1.26 \mathrm{ppm}$ impurity of $\mathrm{CDCl}_{3}$ 


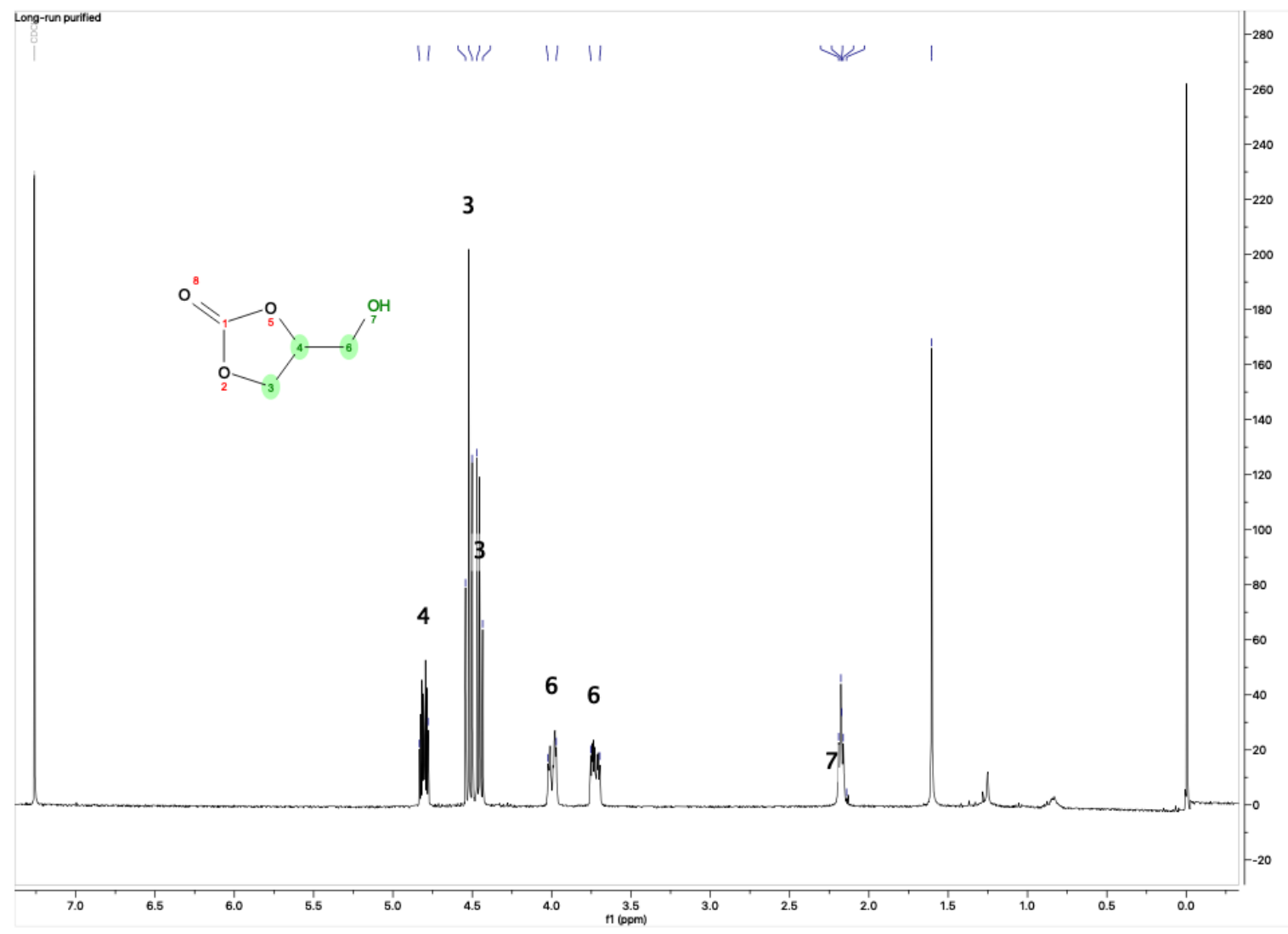

Figure S3: ${ }^{1} \mathrm{H}$ NMR spectrum $\left(\mathrm{CDCl}_{3}\right)$ of column-purified glycerol carbonate. 
Example spectroscopic analysis of a fraction of the flow experiments:

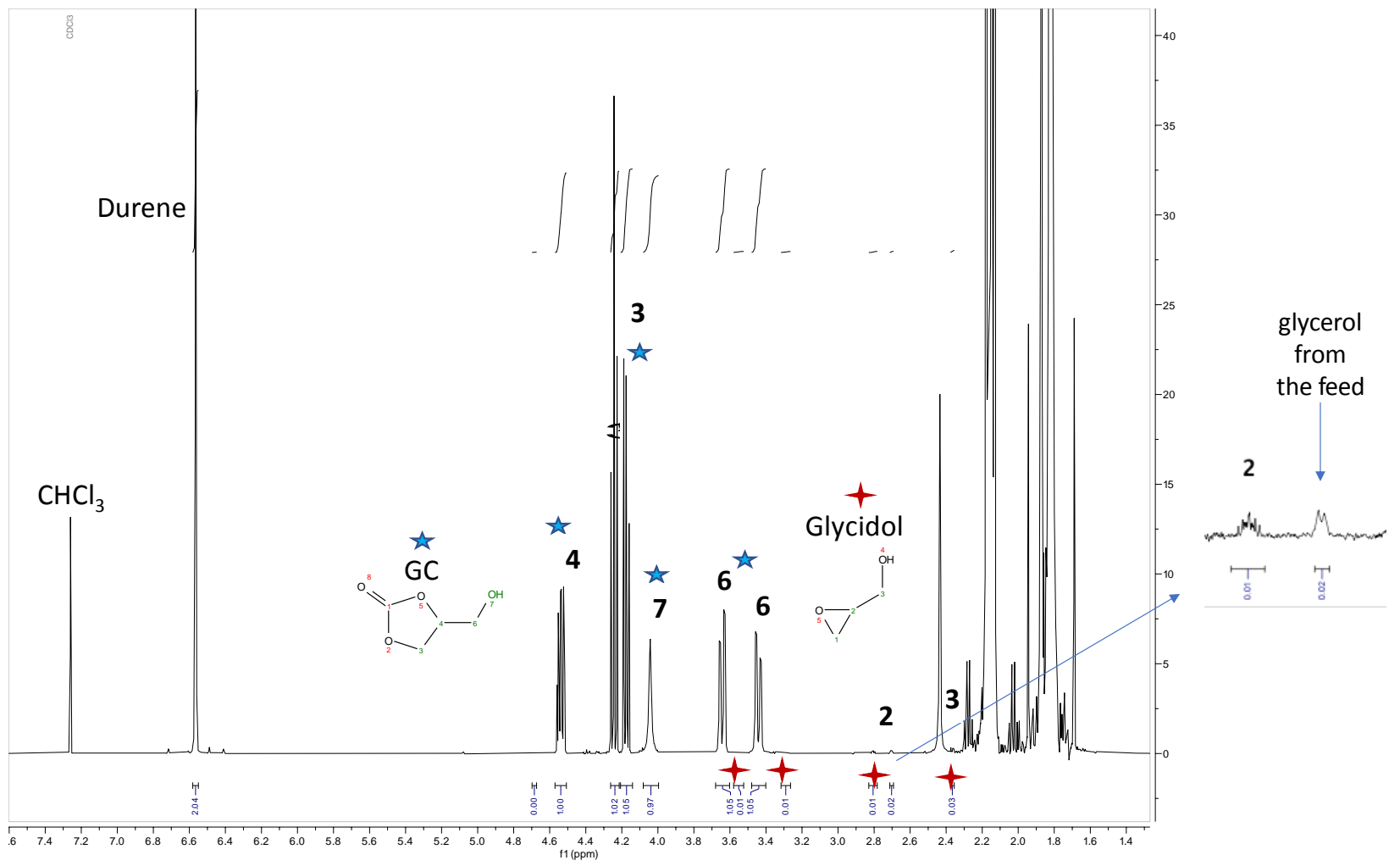

Figure S4: ${ }^{1} \mathrm{H}$ NMR spectrum $\left(\mathrm{CDCl}_{3}\right)$ containing durene as standard, product and starting material (glycidol) and selected integration values. 
NMR analysis of the glycidol feed:

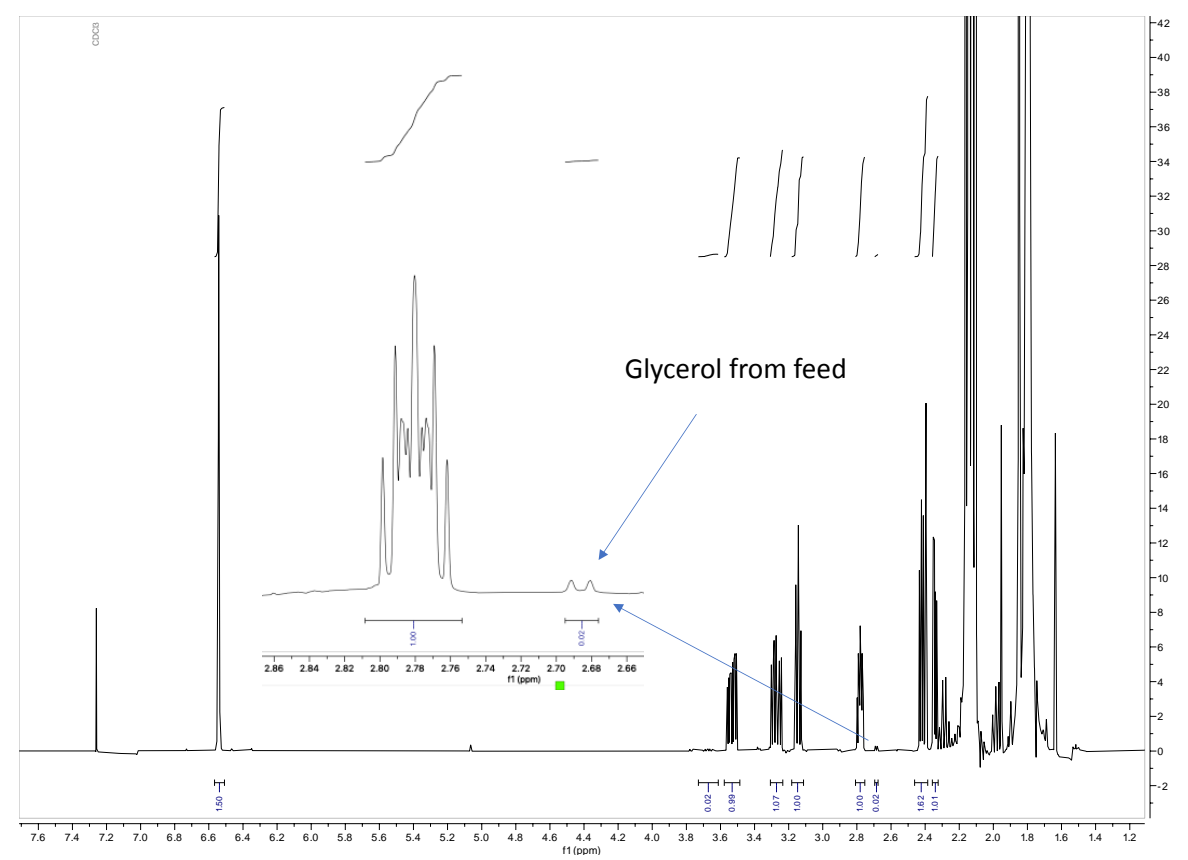

Figure S5. This figure shows the ${ }^{1} \mathrm{H}$ NMR spectra of the glycidol feed solution used for the long-run flow experiment. This spectroscopic analysis demonstrates that trace amount of glycerol was already present prior to the flow reaction. In the zoomed area the peaks that are integrated are the "CH" fragment of glycidol and the $\mathrm{OH}$ group of glycerol. 


\section{Swelling tests performed for 1:}

The swelling test was performed according the procedure reported by M. North and A. Routledge. $^{2}$ The desired resin $(43-89 \mathrm{mg}$ ) was transferred to a $2 \mathrm{~mL}$ syringe fitted with a polypropylene fritted disc with a void volume of $0.15 \mathrm{~mL}$. Solvent (MEK $2 \mathrm{~mL}$ ) was added and the syringe agitated for $1 \mathrm{~h}$ at room temperature using the orbital shaking/stirring. Excess solvent was removed by compressing the syringe piston before slowly withdrawing the piston and allowing the resin to return to its maximum volume. The volume was recorded and the degree of swelling calculated using the formula:

Equation 1: Swelling $\left(m L g^{-1}\right)=\frac{\text { measured volume-void volume }}{\text { mass of resin }}$

Table S2: Comparison of the swelling of fresh catalyst $\mathbf{1}$ employed in the stability test (ST) and the long-run (LR) flow process. Here the results refer to the "high" and "central" part of the packed-bed reactor.

\begin{tabular}{lccccccc}
\hline Catalyst & $\begin{array}{c}\text { Weight } \\
(\mathbf{m g})\end{array}$ & $\begin{array}{c}\text { Volume } \\
\text { after 1 h } \\
(\mathbf{m L})\end{array}$ & $\begin{array}{c}\text { Volume } \\
\mathbf{a f t e r 1 8} \mathbf{~ h} \\
(\mathbf{m L})\end{array}$ & $\begin{array}{c}\text { Volume } \\
\mathbf{a f t e r} \mathbf{2 ~ d} \\
(\mathbf{m L})\end{array}$ & $\begin{array}{c}\text { Swelling } \\
\mathbf{a f t e r} \mathbf{1 ~ h} \\
\left(\mathbf{m L} \cdot \mathbf{g}^{-\mathbf{1}}\right)\end{array}$ & $\begin{array}{c}\text { Swelling } \\
\text { after 18 h } \\
\left(\mathbf{m L} \cdot \mathbf{g}^{-\mathbf{1}}\right)\end{array}$ & $\begin{array}{c}\text { Swelling } \\
\text { after 2 d } \\
\left(\mathbf{m L} \cdot \mathbf{g}^{-\mathbf{1}}\right)\end{array}$ \\
\hline fresh catalyst & 87.9 & 0.3 & 0.3 & 0.4 & 3.4 & 3.4 & 4.55 \\
ST high & 83.4 & 0.15 & 0.15 & 0.2 & 1.8 & 1.8 & 2.4 \\
ST central & 87.3 & 0.2 & 0.2 & 0.2 & 2.3 & 2.3 & 2.3 \\
fresh catalyst & 84.2 & 0.4 & 0.4 & 0.4 & 4.8 & 4.8 & 4.8 \\
LR high & 43.4 & 0.2 & 0.15 & 0.2 & 4.6 & 3.5 & 4.6 \\
LR central & 89.0 & 0.3 & 0.25 & 0.4 & 3.37 & 2.8 & 4.5 \\
\hline
\end{tabular}

Since the swelling tests after $1 \mathrm{~h}$ and $18 \mathrm{~h}$ were as not conclusive, the catalyst was left in contact with the solvent for $48 \mathrm{~h}(2$ days $=2 \mathrm{~d})$, and in this case it was evident that mechanical damage of the catalyst was affecting the swelling. This was even more evident for the catalyst batches used in the stability test (cycles) compared to the long-run experiment. These combined swelling tests gave a simple confirmation of what is possible to observe from a visual analysis of the packed-bed reactor. After the stability test cycles the catalyst was not able to fill the original volume it was occupying, whereas the physical state of the catalyst before and after the long-run flow process was the same.

\footnotetext{
${ }^{2}$ C. Amadi-Kamalu, H. Clarke, M. McRobie, J. Mortimer, M. North, Y. Ran, A. Routledge, D. Sibbald, M. Tickias, K. Tse, H. Willway, ChemistryOpen 2020, 9, 431-441, DOI: 10.1002/open.202000030.
} 
Table S3: Swelling test of the catalysts employed in the batch screening, the concentration of the active sites was calculated by $f_{\exp } \cdot$ swelling $^{-1}$.

\begin{tabular}{lccccc}
\hline Catalyst & $\begin{array}{c}\text { Weight } \\
(\mathbf{m g})\end{array}$ & $\begin{array}{c}\text { Volume } \\
\text { after } \mathbf{~ 1 8 ~ h} \\
(\mathbf{m L})\end{array}$ & $\begin{array}{c}\text { Swelling } \\
\text { after } \mathbf{~ 1 8 ~ h} \\
\left(\mathbf{m L} \cdot \mathbf{g}^{-1}\right)\end{array}$ & $\begin{array}{c}f_{\text {exp }} \\
\left(\mathbf{m m o l} \cdot \mathbf{g}^{-1}\right)\end{array}$ & $\begin{array}{c}\text { [Active sites] } \\
\mathbf{m m o l} \cdot \mathbf{m L} \mathbf{- 1}\end{array}$ \\
\hline TBD@Merrifield , 1 & 44.6 & 0.55 & 12.33 & 0.307 & 0.025 \\
TBD@Wang, 2 & 44.7 & 0.35 & 7.83 & 0.643 & 0.082 \\
TBD@JandaJel, 3 & 44.1 & 0.55 & 12.47 & 0.426 & 0.034 \\
TBD-2@Merrifield, 4 & 47.8 & 0.65 & 13.60 & 0.379 & 0.028 \\
TBD@Barlos, 5 & 40.3 & 0.35 & 8.68 & 0.993 & 0.114 \\
DBU@polystyrene, 8 & 49.9 & 0.35 & 7.01 & 1.91 & 0.272
\end{tabular}

Note that the relative activity of these supported catalysts seems to be inversely related to the amount of active sites within the polymer molecules. 


\section{Comparison of fresh and used catalyst by IR analysis:}

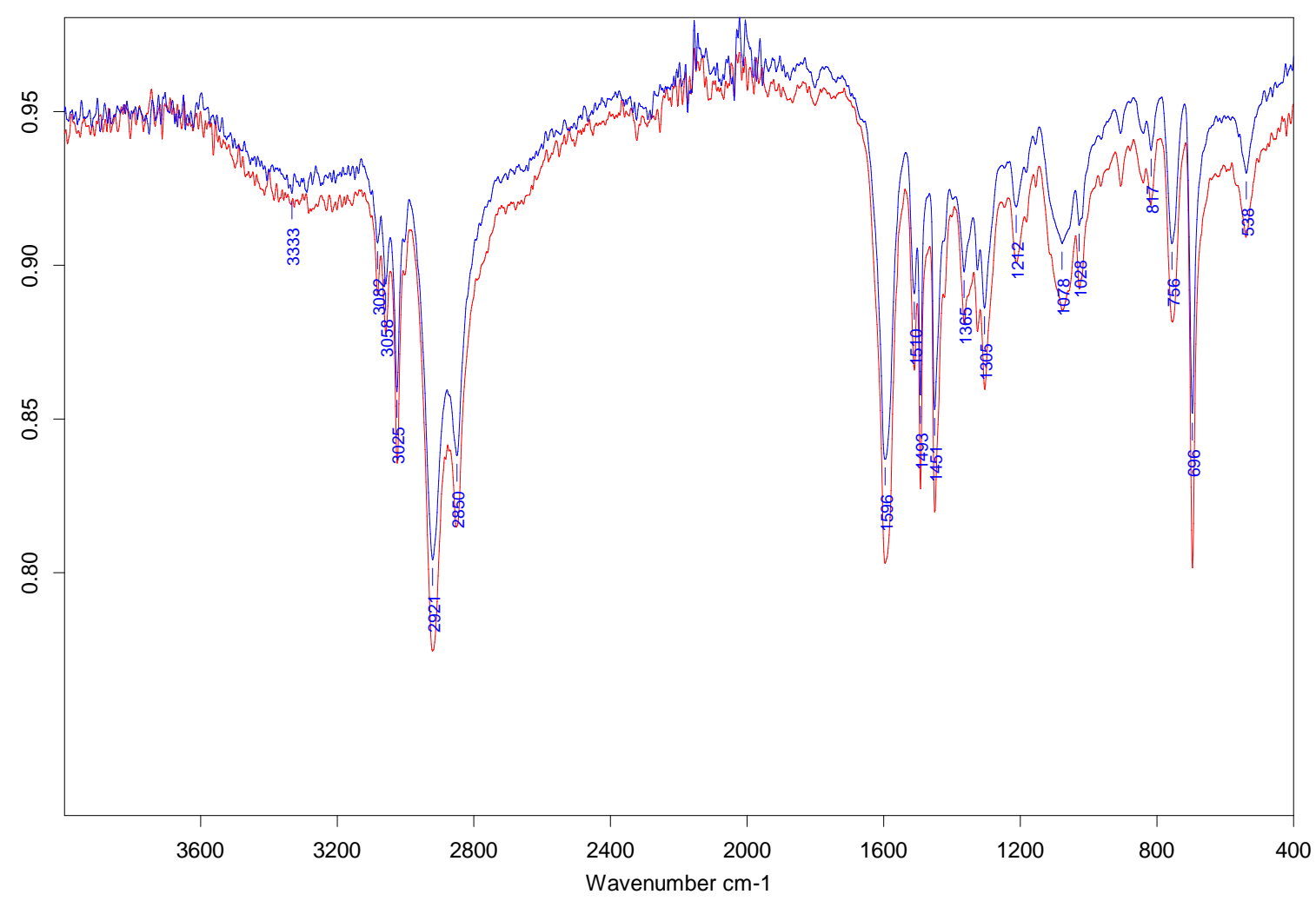

Figure S6: FT-IR spectroscopic analysis of the fresh catalyst (red color) and the used one (blue color).

From the comparison of the IR spectra of the fresh and used catalyst employed in the stability tests in flow ( 8 cycles in total), there is no evident sign of chemical modification of the structure. 


\section{Batch optimization experiments:}

General conditions: In a typical experiment we weighed the appropriate amount of catalyst and charged the reactor (10 $\mathrm{mL}$ stainless steel autoclave). The reactor was then sealed and a leak test was performed using $\mathrm{CO}_{2}$ as gas (15-20 bar). The reactor was pressurized at 2 bar with a constant flow of $\mathrm{CO}_{2}$ while charging it with a solution of the substrate (glycidol) and closed. Then the reaction mixture was stirred and the reactor was first heated at the desired temperature after which it brought to the desired isobaric pressure by adding $\mathrm{CO}_{2}$. After the chosen reaction time, the system was cooled down, the product collected and the reactor washed with EtOAc. The combined organic layers were then filtered, and concentrated in vacuo. To a sample was added DMSO- $\mathrm{d}_{6}$ and a known amount of internal standard (durene) following analysis by ${ }^{1} \mathrm{H}$ NMR.

Table S4: Temperature effect using catalyst 1: ${ }^{a}$

\begin{tabular}{ccc}
\hline Entry & $\begin{array}{c}\mathbf{T} \\
\left({ }^{\mathbf{C}} \mathbf{C}\right)\end{array}$ & $\begin{array}{c}\text { yield of glycerol carbonate } \\
(\mathbf{\%})\end{array}$ \\
\hline 1 & 50 & 28 \\
2 & 60 & 58 \\
3 & 70 & 78 \\
4 & 80 & $76^{\boldsymbol{b}}$
\end{tabular}

a $5 \mathrm{bar}$ (isobaric conditions) $\mathrm{CO}_{2}, 1.8 \mathrm{M}$ (MEK), $1 \mathrm{mmol}$ glycidol, $0.3 \mathrm{mmol} \%$ catalyst loading, $18 \mathrm{~h}$. IS (durene) was added by weight to a separate vial, the crude was filtered to separate the catalyst and added to the internal standard durene following analysis by ${ }^{1} \mathrm{H}$ NMR $\left(\mathrm{CDCl}_{3}\right)$. Catalyst 1 was dried overnight under vacuum prior to experiments. ${ }^{b}$ At higher temperature hydrolysis of either glycidol or glycerol carbonate becomes an issue with $16 \%$ glycerol observed in the reaction mixture.

Table S5: Pressure variations using various heterogeneous catalysts. ${ }^{a}$

\begin{tabular}{|c|c|c|c|}
\hline Entry & Cat & $\begin{array}{c}P \\
\text { (bar) }\end{array}$ & $\begin{array}{c}\text { yield } \\
(\%)\end{array}$ \\
\hline 1 & TBD@SBA15 & 2 & 20 \\
\hline 2 & TBD@SBA15 & 5 & 92 \\
\hline 3 & TBD@Merrifield & 5 & 95 \\
\hline 4 & DBU@PS & 5 & 94 \\
\hline 5 & TBD@SBA15 & 5 & 68 \\
\hline 6 & TBD@MCM41 & 5 & 87 \\
\hline 7 & TBD@SBA15 & 10 & 98 \\
\hline 8 & TBD@SBA15 & 15 & 98 \\
\hline 9 & TBD@MCM41 & 15 & 88 \\
\hline 10 & TBD@Merrifield & 15 & 95 \\
\hline \multicolumn{4}{|c|}{$\begin{array}{l}{ }^{a} \text { Isobaric conditions } \mathrm{CO}_{2}, 4.99 \mathrm{mmol} \text { glycidol (neat), } 0.20 \mathrm{~mL} \text { MEK, } 0.3 \mathrm{mmol} \% \\
\text { catalyst loading, } 24 \mathrm{~h} \text {. IS (durene) was added by weight to a separate vial, the crude } \\
\text { was filtered to separate the catalyst and added to the internal standard durene following } \\
\text { analysis by }{ }^{1} \mathrm{H} \text { NMR }\left(\mathrm{CDCl}_{3}\right) \text {. Note that for entry } 5 \text {, this pressure was applied only at } \\
\text { the beginning of the reaction and thus decreased gradually overtime as } \mathrm{CO}_{2} \text { was being } \\
\text { consumed. }\end{array}$} \\
\hline
\end{tabular}




\section{Synthesis of precursors:}

\section{Precursor 1:}<smiles>OCC(O)CN1CCCN2CCCN=C21</smiles>

8-tetrahydro-2H-pyrimido[1,2-a]pyrimidin-1(6H)-yl)propane-1,2-diol: Freshly distilled oxiran-2-ylmethanol (2.64 mmol, 1 equiv) was added to a stirred solution of 1,3,4,6,7,8hexahydro- $2 \mathrm{H}$-pyrimido[1,2-a] pyrimidine $\left(2.64 \mathrm{mmol}, 1\right.$ equiv) in toluene $(8.8 \mathrm{~mL})$ at $50^{\circ} \mathrm{C}$. The reaction mixture was stirred at $50{ }^{\circ} \mathrm{C}$ for $24 \mathrm{~h}$ and filtered with a PTFE filter ( 0.45 micron), and the solvent was removed under reduced pressure. Yield: $99 \% .{ }^{1} \mathbf{H}$ NMR $\left(\mathrm{CDCl}_{3}, 400\right.$ MHz): $\delta=1.75-1.81(\mathrm{~m}, 2 \mathrm{H}), 1.89-1.98(\mathrm{~m}, 2 \mathrm{H}), 3.07-3.12(\mathrm{~m}, 4 \mathrm{H}), 3.15-3.28(\mathrm{~m}, 4 \mathrm{H})$, $3.34-3.45(\mathrm{dd}, 2 \mathrm{H}), 3.48-3.49(\mathrm{~d}, 1 \mathrm{H}), 3.67-3.72(\mathrm{~m}, 1 \mathrm{H}) ;{ }^{13} \mathbf{C}-\mathbf{N M R}\left(\mathrm{CDCl}_{3}, 100 \mathrm{MHz}\right)$ : $\delta=22.7,22.8,42.2,47.9,48.2,48.4,53.3,63.7,71.0,152.7$. CHNO (\%) analyses found (theoretical): C 55.28 (56.32), H 10.51 (8.98), N 19.94 (19.69), O 14.25 (15.01); HRMS (ESI+, MeOH): $m / z 214.1546$ (calc. 214.1550); FT-IR (neat, $v$ in $\mathrm{cm}^{-1}$ ): 3296, 2847, 1577 , $1515,1035,1044$.

\section{Precursor 2:}<smiles>CC(O)CN1CCCN2CCCN=C21</smiles>

1-(3,4,7,8-tetrahydro-2H-pyrimido[1,2-a]pyrimidin-1 $(6 H)$-yl)propan-2-ol: ${ }^{3}$ 2-methyloxirane (5.39 mmol, 1.5 equiv) was added to a stirred solution of $1,3,4,6,7,8$-hexahydro- $2 \mathrm{H}$ pyrimido[1,2-a]pyrimidine $(3.59 \mathrm{mmol}, 1$ equiv) in toluene $(10 \mathrm{~mL})$. The mixture was stirred at $80{ }^{\circ} \mathrm{C}$ for $16 \mathrm{~h}$. Then the crude was cooled down to r.t., and the solvent was removed under reduced pressure. Yield: $99 \%$. The NMR data of the product were compared against the previously reported data described in the literature. ${ }^{1} \mathbf{H}$ NMR (toluene-d $8,400 \mathrm{MHz}$ ): $\delta=1.18$ $(\mathrm{d}, 3 \mathrm{H}), 1.46(\mathrm{~m}, 4 \mathrm{H}), 2.50(\mathrm{~m}, 1 \mathrm{H}), 2.58(\mathrm{~m}, 1 \mathrm{H}), 2.64(\mathrm{~m}, 2 \mathrm{H}), 2.69(\mathrm{~m}, 1 \mathrm{H}), 2.82(\mathrm{~m}, 1 \mathrm{H})$, $2.97(\mathrm{dd}, 1 \mathrm{H}), 3.22(\mathrm{~m}, 2 \mathrm{H}), 3.51(\mathrm{dd}, 1 \mathrm{H}),, 4.24(\mathrm{qdd}, 1 \mathrm{H}):{ }^{13} \mathbf{C}$ NMR (toluene-d8, $\left.101 \mathrm{MHz}\right)$ : $\delta 154.22,68.43,60.77,48.75,48.65,48.51,43.17,24.93,22.36$.

\footnotetext{
${ }^{3}$ P. Horeglad, A. Litwińska, G. Z. Żukowska, D. Kubicki, G. Szczepaniak, M. Dranka, J. Zachara, Appl. Organomet. Chem. 2013, 27, 328-336, DOI: 10.1002/aoc.2978.
} 


\section{Synthesis of the heterogeneous catalysts:}

General procedure A for supported catalysts: $\mathrm{NaH}$ (95\%, 3 equiv) was added portion-wise to a stirred solution of 3-(3,4,7,8-tetrahydro- $2 \mathrm{H}$-pyrimido[1,2-a] pyrimidin- $1(6 H)$-yl)propane1,2-diol ( 1 equiv) at $0{ }^{\circ} \mathrm{C}$ and under $\mathrm{N}_{2}$ atmosphere. The suspension was stirred for $15 \mathrm{~min}$ and then added through a cannula to a closed flask containing the respective resin support $(0.5$ equiv) in DMF $(20 \mathrm{~mL})$ under $\mathrm{N}_{2}$. Then the suspension was shaken for 2 days at r.t. The obtained heterogeneous catalyst was characterized by IR to assess the presence of $\mathrm{C}=\mathrm{N}$ "stretching" absorptions. Elemental analysis was additionally performed to quantify the amount of precursor (functionalization degree, $\mathbf{f}$ ) onto the support, and finally gel phase ${ }^{13} \mathrm{C}$ NMR analysis was also carried out where possible.

General procedure B for supported catalysts: A solution of 3-(3,4,7,8-tetrahydro- $2 \mathrm{H}$ pyrimido[1,2-a]pyrimidin-1(6H)-yl)propane-1,2-diol (1 equiv) in DCM (10 mL) was added at $0{ }^{\circ} \mathrm{C}$ and under $\mathrm{N}_{2}$ atmosphere to a shaken suspension of a Barlos resin (0.5 equiv) and triethylamine (TEA, 2 equiv) in DCM. Then the reaction suspension was shaken for 3 days at r.t. The obtained catalyst was characterized by IR to assess the presence of $\mathrm{C}=\mathrm{N}$ "stretching" absorptions. Elemental analysis was additionally performed to quantify the amount of precursor (functionalization degree, $\mathbf{f}$ ) onto the support, and finally gel phase ${ }^{13} \mathrm{C} N \mathrm{NR}$ analysis was also carried out where possible.

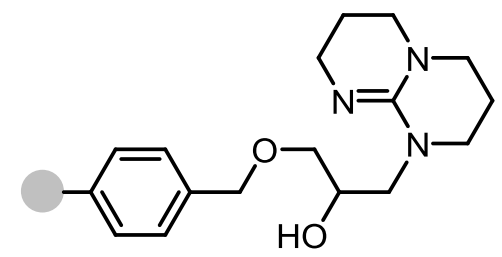

1. TBD@Merrifield

Synthesis of Merrifield supported catalyst TBD@ Merrifield (1): $\mathrm{NaH} 95 \%$ (3 equiv) was added portion-wise to a stirred solution of 3-(3,4,7,8-tetrahydro- $2 \mathrm{H}$-pyrimido[1,2-a] pyrimidin-1 $(6 H)$-yl)propane-1,2-diol (1 equiv) at $0{ }^{\circ} \mathrm{C}$ and under a $\mathrm{N}_{2}$ atmosphere. The suspension was stirred for $15 \mathrm{~min}$ and then added through a cannula to a closed flask containing (chloromethyl)polystyrene (Novabiochem, $1.5 \mathrm{mmol} / \mathrm{g}, 1 \% \mathrm{DVB}, 100-200 \mathrm{mesh}$ ) (0.5 equiv) in DMF $(20 \mathrm{~mL})$ under $\mathrm{N}_{2}$. Then the suspension was shaken for 5 days at r.t. CHNO (\%) Analyses: C 82.98, H 7.78, N 3.92, O 3.02; fexp: 0.933 mmol/g (note: entry 15, Table 1); FTIR (neat, $v$ in $\left.\mathrm{cm}^{-1}\right): 3024,2921,1596,1450,696 ;{ }^{13} \mathbf{C ~ N M R}\left(\mathrm{CDCl}_{3}, 126 \mathrm{MHz}\right): \delta=152.09$, 70.23, 64.09, 55.71, 48.22, 41.52, 22.92, 22.66 .

Note that also catalyst batches with other functionalization degrees were prepared similarly:

Table 1: entries 1-9, $16+17: \mathbf{f}_{\exp }=0.307 \mathrm{mmol} / \mathrm{g}$, using $0.6 \mathrm{mmol} / \mathrm{g}, 1 \% \mathrm{DVB}, 100-200 \mathrm{mesh}$, Merrifield resin.

Table 1: entries 10-14: $\mathbf{f}_{\mathbf{e x p}}=0.740 \mathrm{mmol} / \mathrm{g}$ 


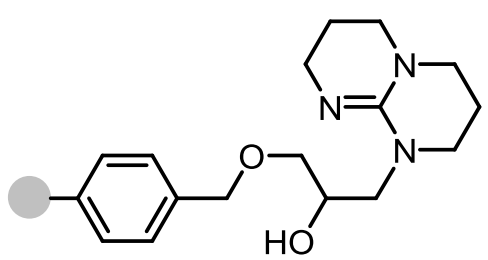

2. TBD@Wang

Synthesis of Wang supported catalyst (2): prepared according general procedure A using Wang resin (IRIS biotech, $1.2 \mathrm{mmol} / \mathrm{g}, 1 \% \mathrm{DVB}, 100-200 \mathrm{mesh}$ ). CHN (\%) Analyses: C 80.23, H 7.31, N 2.70; fexp: 0.643 mmol/g; FT-IR (neat, $v$ in $\mathrm{cm}^{-1}$ ): 3024, 2921, 1599, 1450, 697.

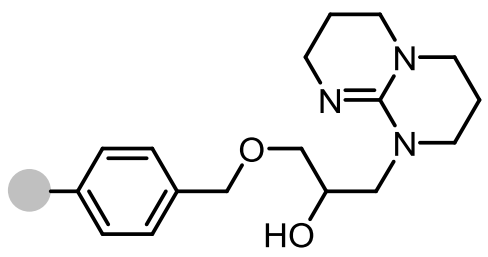

3. TBD@JandaJel

Synthesis of JandaJel supported catalyst (3): prepared according general procedure A from Jandajel (Aldrich, $1 \mathrm{mmol} / \mathrm{g}$ resin. 1\% cross-linked, 100-200 mesh). CHN (\%) Analyses: C 87.09, H 7.55, N 1.79. fexp: 0.426 mmol/g; FT-IR (neat, $v$ in $\mathrm{cm}^{-1}$ ): 3025, 2919, 1600, 1451 , $696 ;{ }^{13} \mathrm{C} \mathrm{NMR}\left(\mathrm{CDCl}_{3}, 126 \mathrm{MHz}\right): \delta=145.01,69.67,63.64,55.21,48.80,47.85,43.14,22.77$, 22.49 .

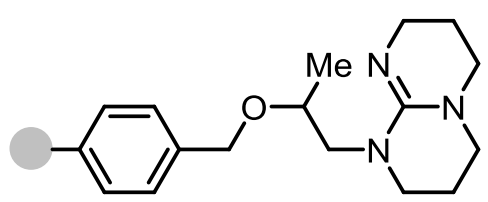

4. TBD-2@Merrifield

Synthesis of Merrifield supported catalyst TBD-2@Merrifield (1-(3,4,7,8-tetrahydro-2Hpyrimido[1,2-a]pyrimidin-1(6H)-yl)propan-2-ol supported catalyst) (4): synthesized according general procedure A employing a Merrifield resin (Novabiochem, $0.6 \mathrm{mmol} / \mathrm{g} 1 \%$ DVB, 100-200 mesh). CHN (\%) Analyses: C 89.50, H 7.69, N 1.59; fexp: 0.379 mmol/g; FTIR (neat, $v$ in $\mathrm{cm}^{-1}$ ): 3025, 2921, 1600, 1451, 695. 


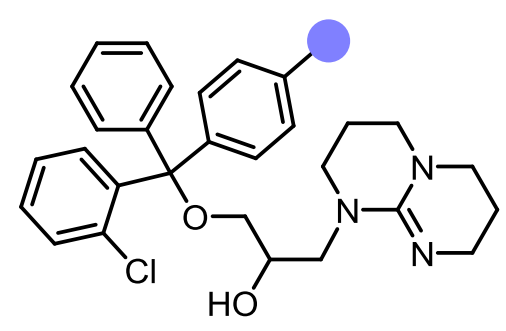

5. TBD@Barlos

Synthesis of Barlos supported catalyst (5): prepared according general procedure B from Barlos Resin (IRIS biotech, 1.6 mmol/g, 1\% DVB, 100-200 mesh). CHN (\%) Analyses: C 74.84, H 6.54, N 4.25; fexp: 0.993 mmol/g; FT-IR (neat, $v$ in $\mathrm{cm}^{-1}$ ): 3314, 3024, 2922, 1594, 1446, 698.

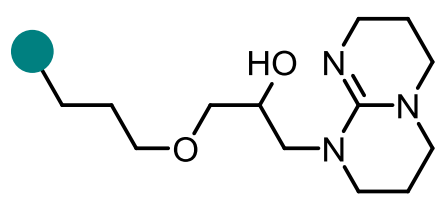

7. TBD@SBA15

Synthesis of silica supported catalyst [TBD@SBA-15], (7): prepared according to a procedure reported in the literature: ${ }^{4} \mathbf{f}_{\exp }: 0.921 \mathrm{mmol} / \mathrm{g}, \mathrm{S}_{\text {BET }}: 859.5 \mathrm{~m}^{2} / \mathrm{g} \mathrm{dp}: 5.073 \mathrm{~nm} \mathrm{Vp}$ : $0.974 \mathrm{cc} / \mathrm{g}$.

Note that supported catalysts (6) and (8), see below, were purchased from commercial suppliers:<smiles>OC(CC(O)c1ccncc1)c1ccncc1</smiles>

6. 4-poly-vinylpyridine

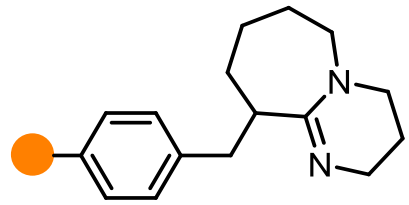

8. DBU@Polystyrene

Details for 6: Fluka, 81391 (25 g bottle), poly-(4-vinyl-pyridine), (2\% DVB)

Details for 8: Aldrich, 595128-5g, 1,8-diazabicyclo[5.4.0]undec-7-ene, polymer bound (1\%DVB, 100-200 Mesh)

\footnotetext{
${ }^{4}$ D. Meloni, R. Monaci, Z. Zedde, M. G. Cutrufello, S. Fiorilli, I. Ferino, Appl. Catal. B: Environ. 2011, 102, 505-514, DOI: 10.1016/j.apcatb.2010.12.032.
} 
Copies of relevant NMR and IR spectra:

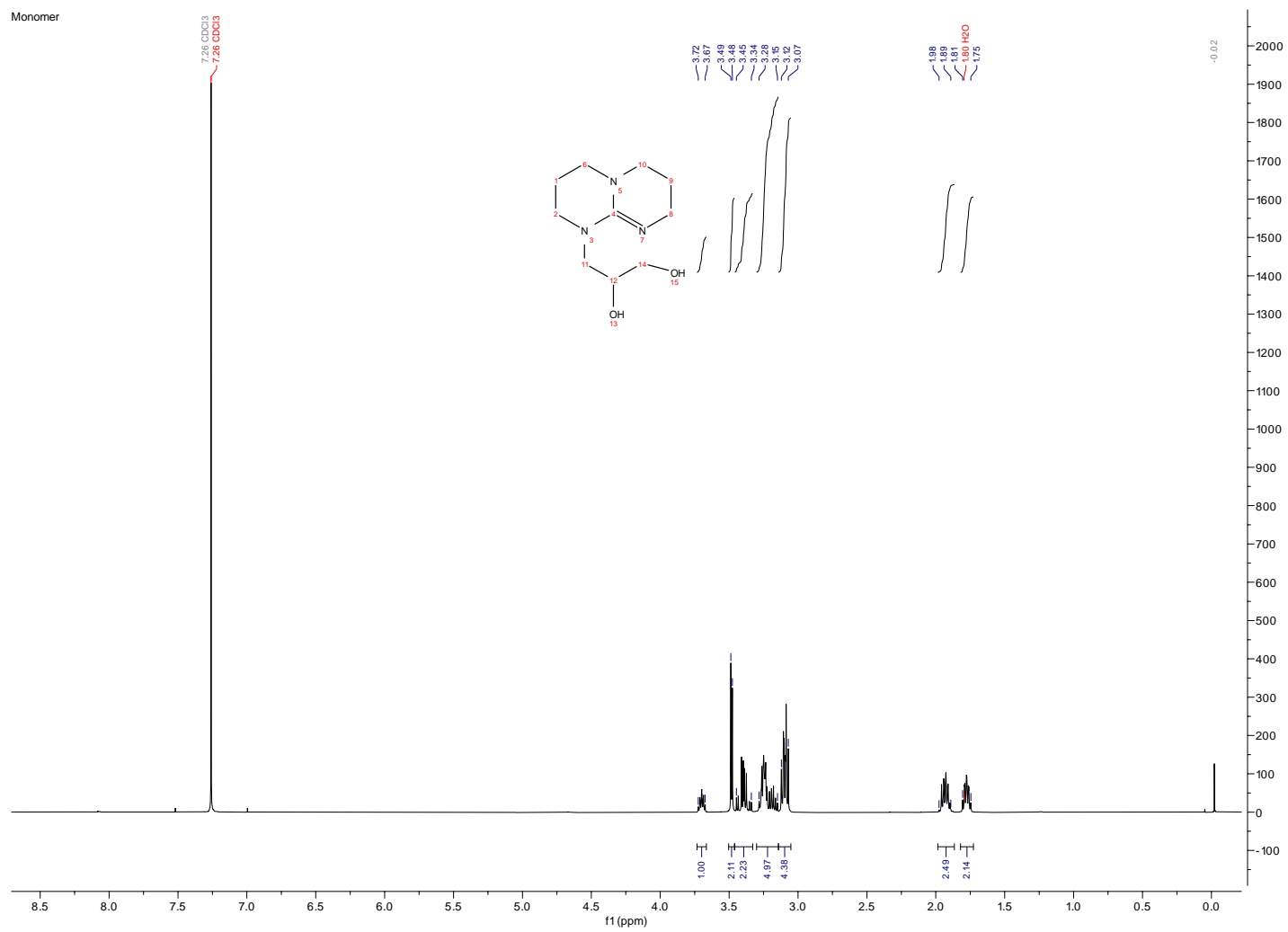

Figure S7: ${ }^{1} \mathrm{H}$ NMR $\left(\mathrm{CDCl}_{3}\right)$ spectrum for Precursor 1.

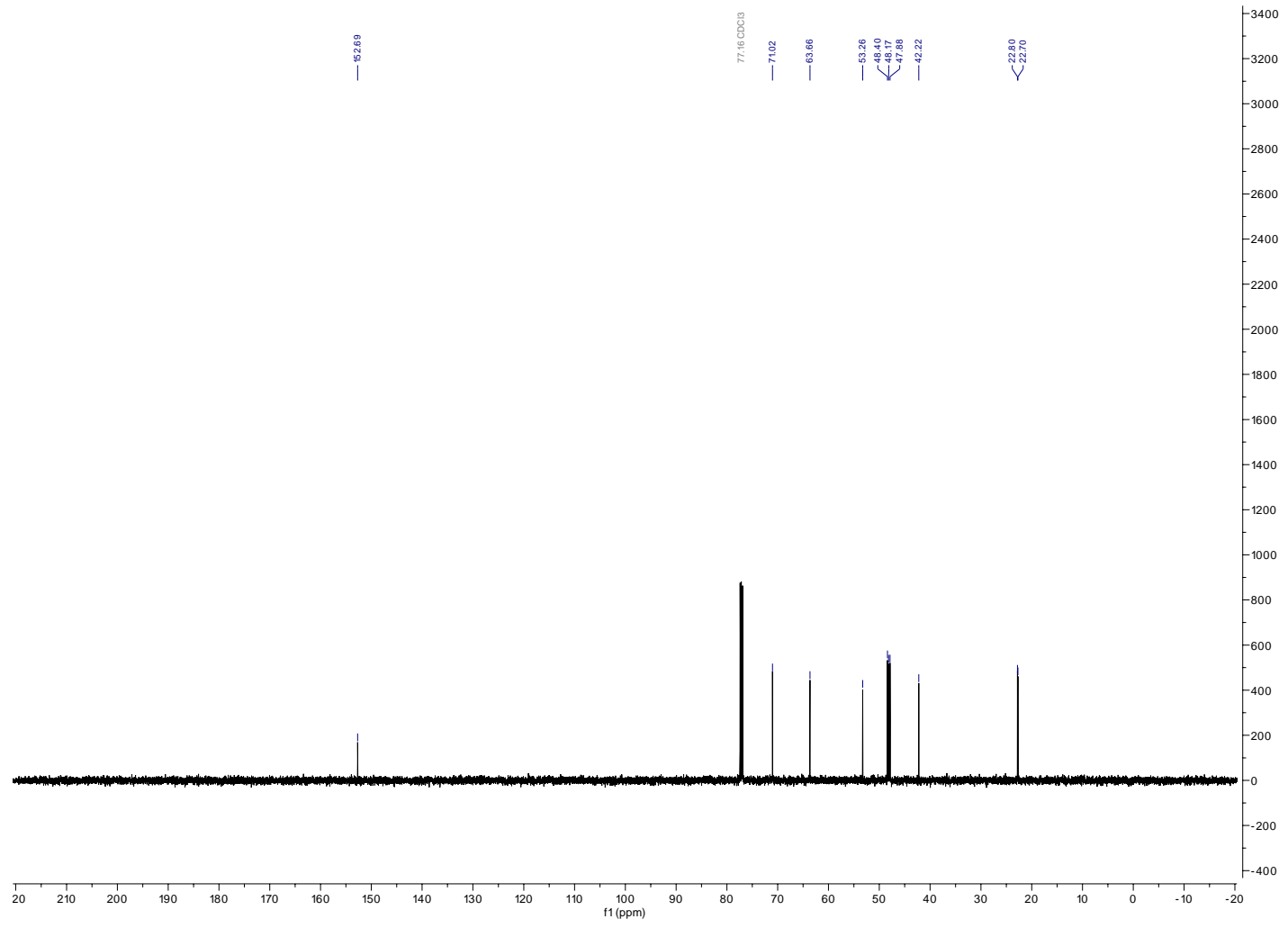

Figure S8: ${ }^{13} \mathrm{C}$ NMR $\left(\mathrm{CDCl}_{3}\right)$ spectrum for Precursor 1. 


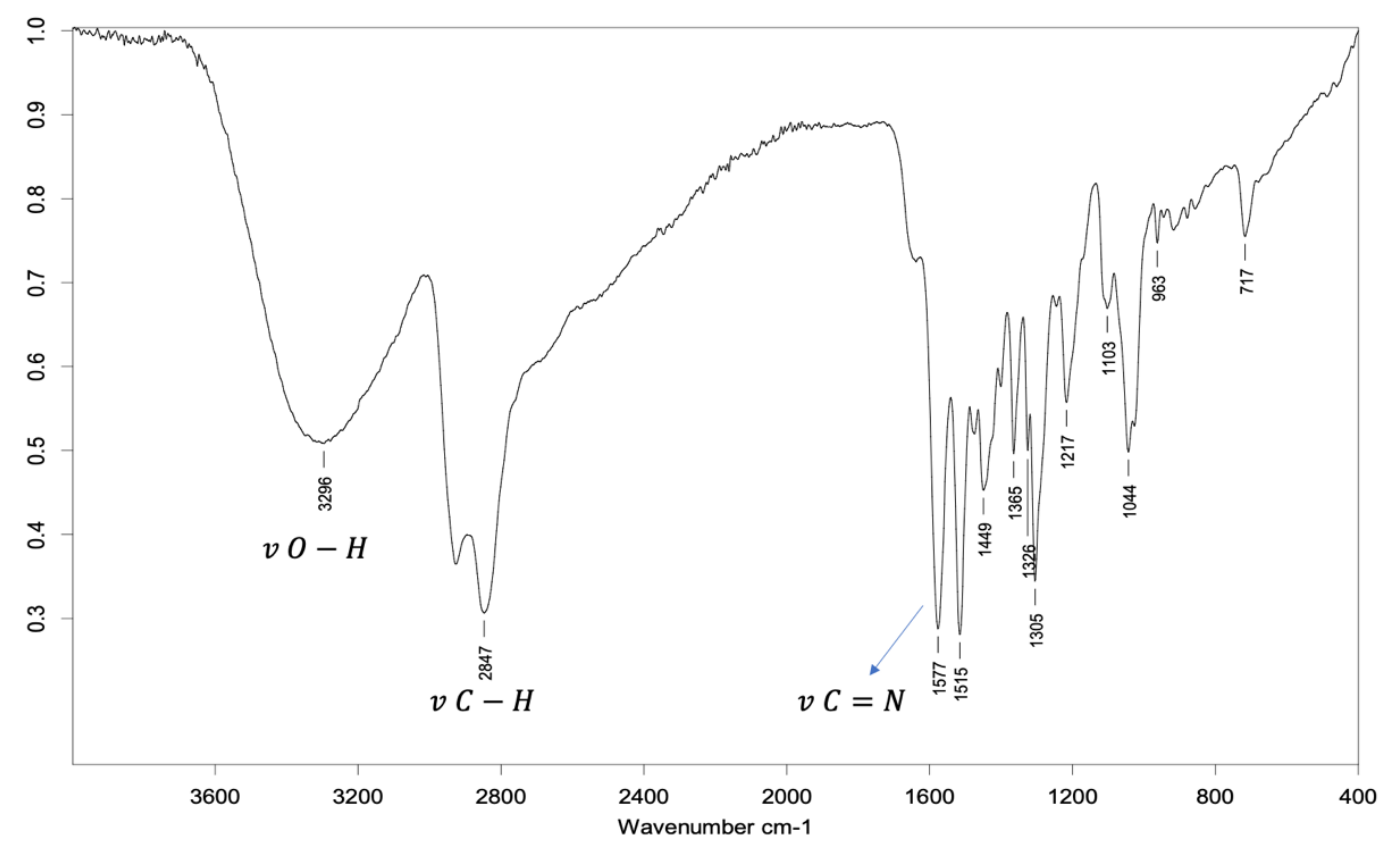

Figure S9: IR spectrum (neat) for Precursor 1. 


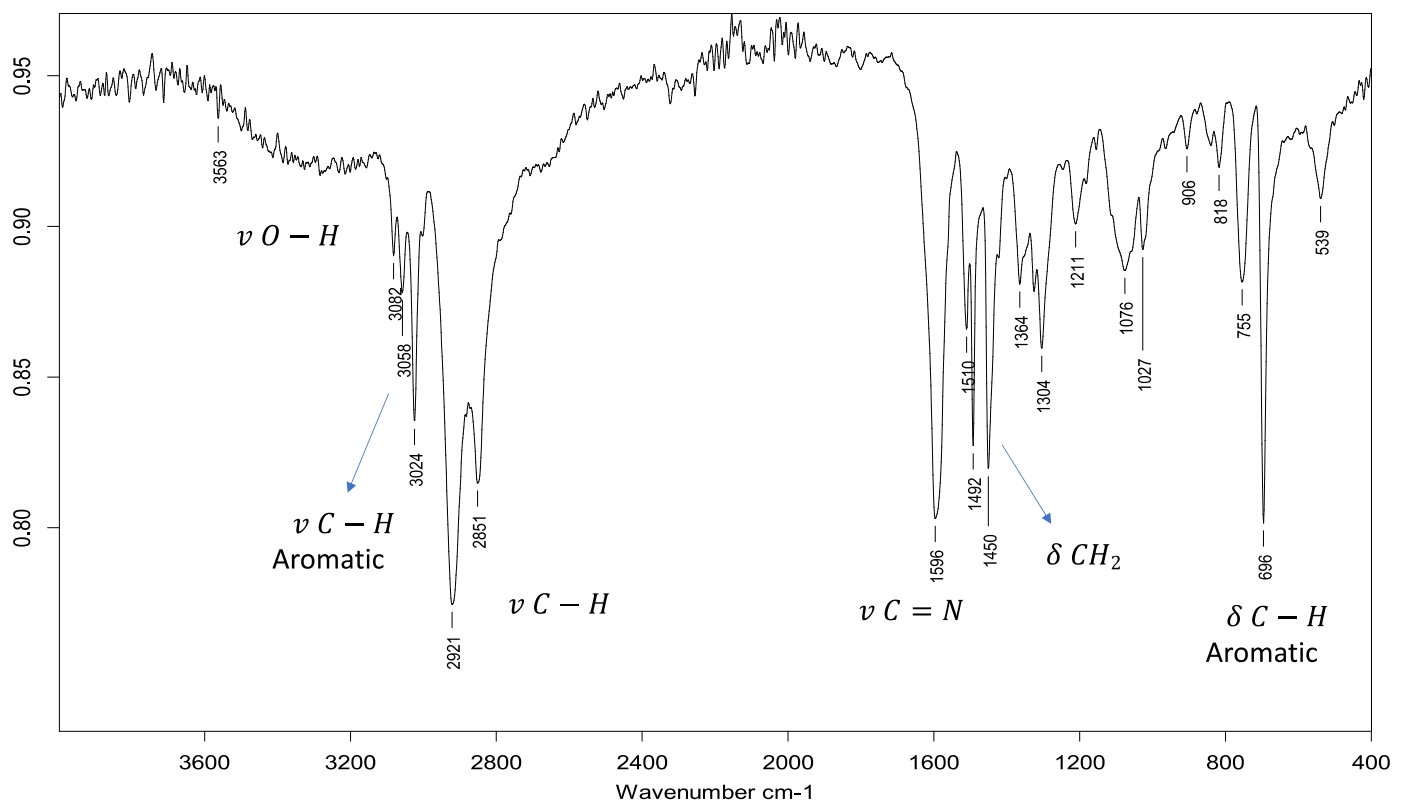

Figure S10: IR spectrum (neat) for TBD@Merrifield (1).

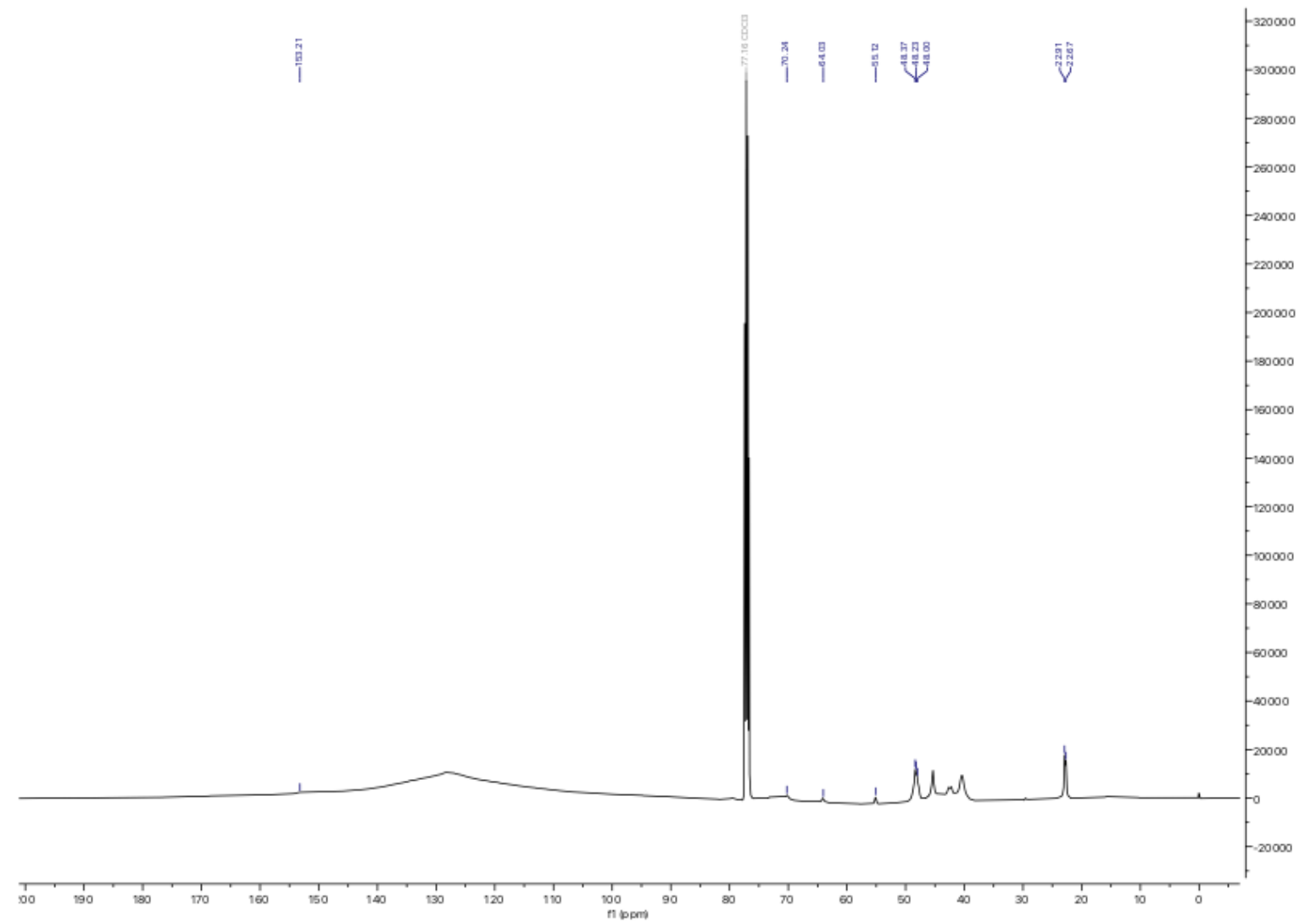

Figure S11: ${ }^{13} \mathrm{C}$ NMR $\left(\mathrm{CDCl}_{3}\right)$ spectrum for TBD@Merrifield (1). 


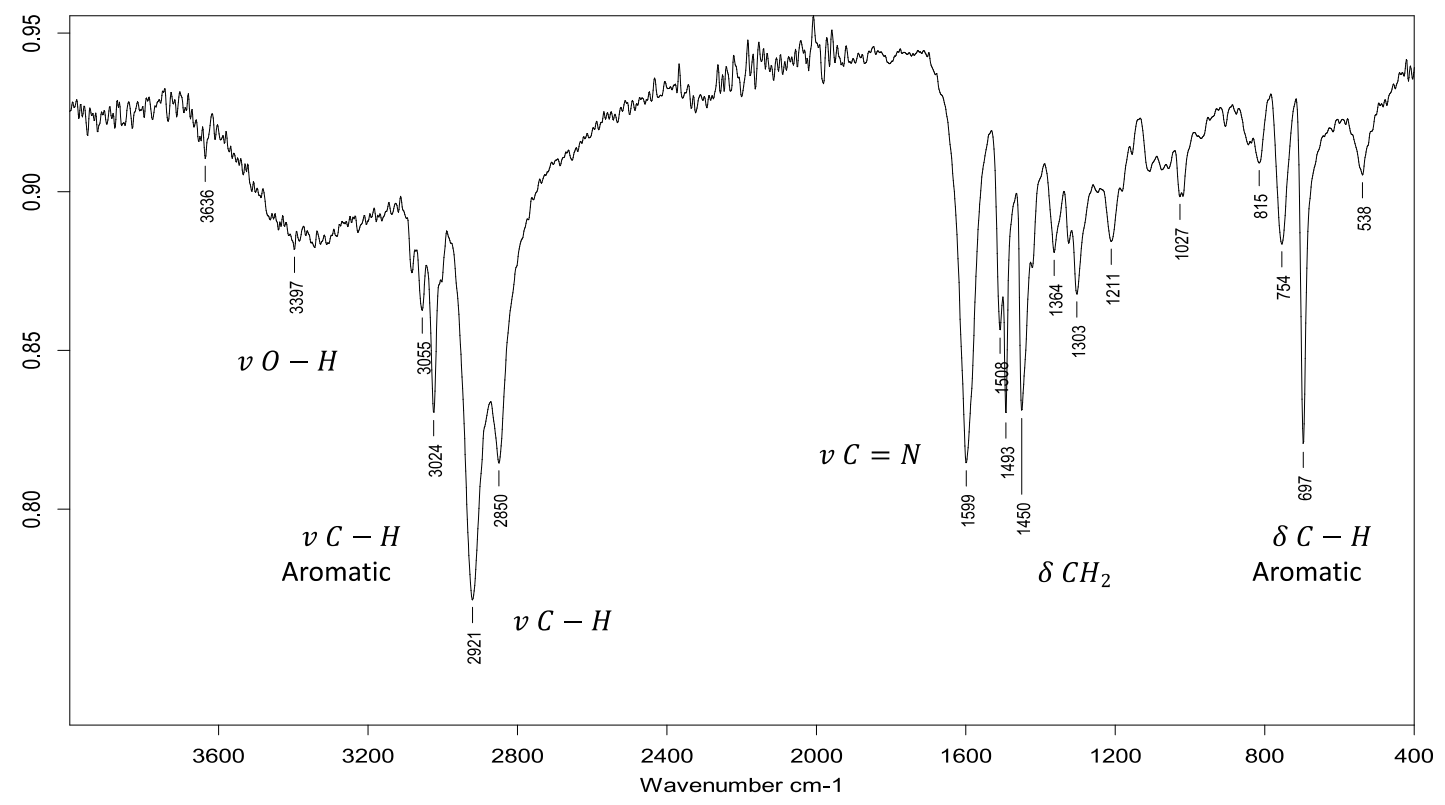

Figure S12: IR spectrum (neat) for TBD@Wang (2). 


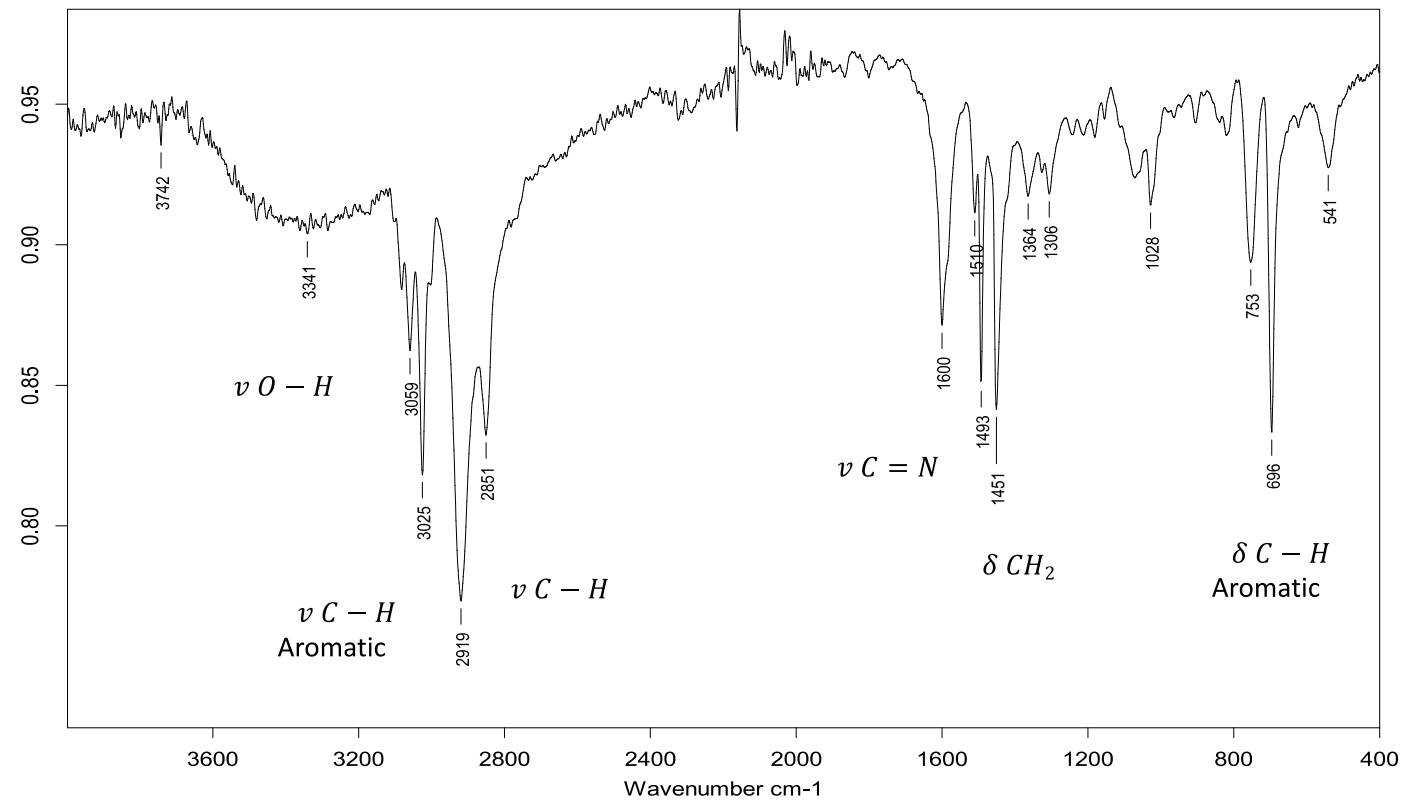

Figure S13: IR spectrum (neat) for TBD@JandaJel (3).

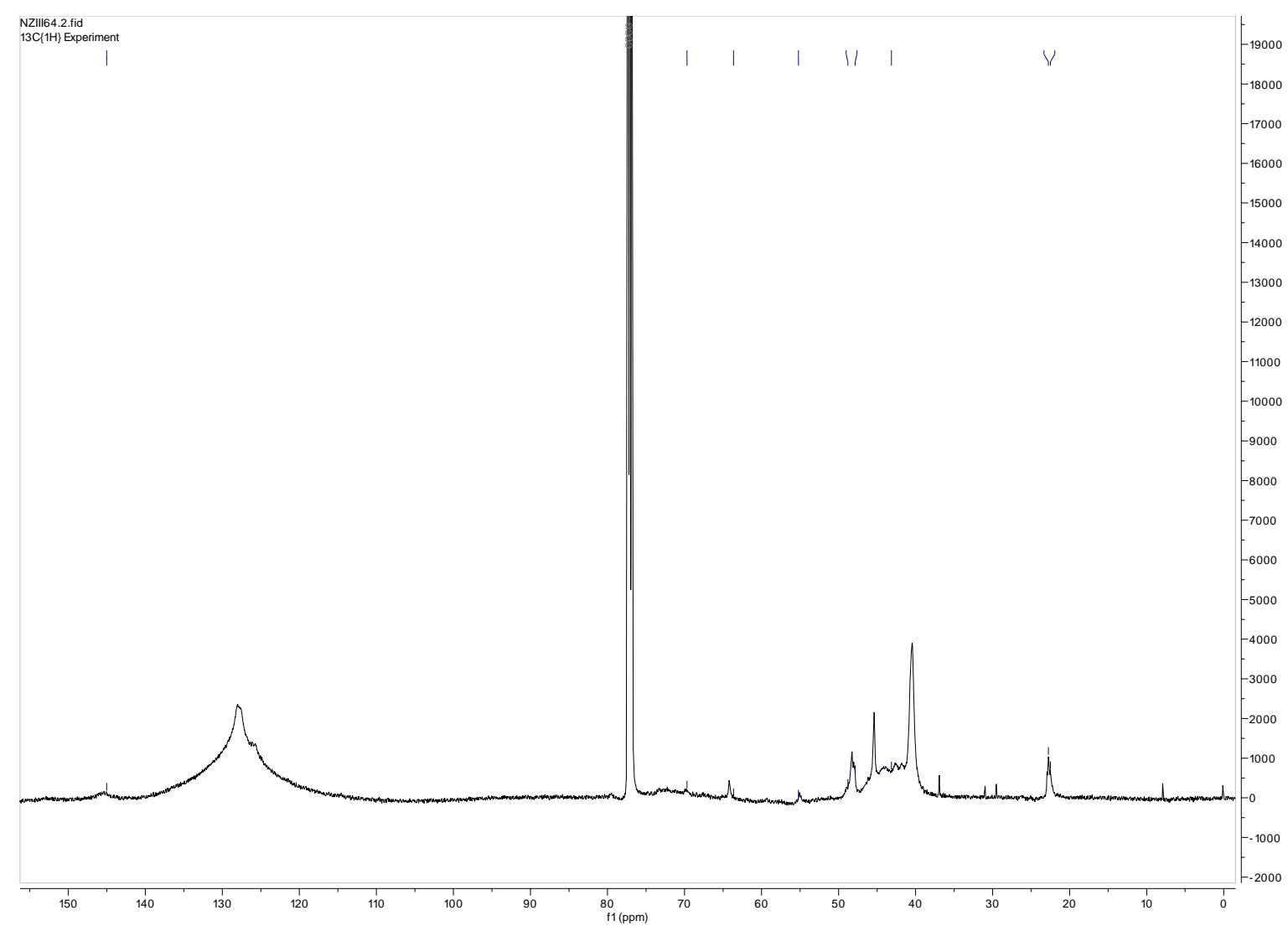

Figure S14: ${ }^{13} \mathrm{C}$ NMR $\left(\mathrm{CDCl}_{3}\right)$ spectrum for TBD@ JandaJel (3). 


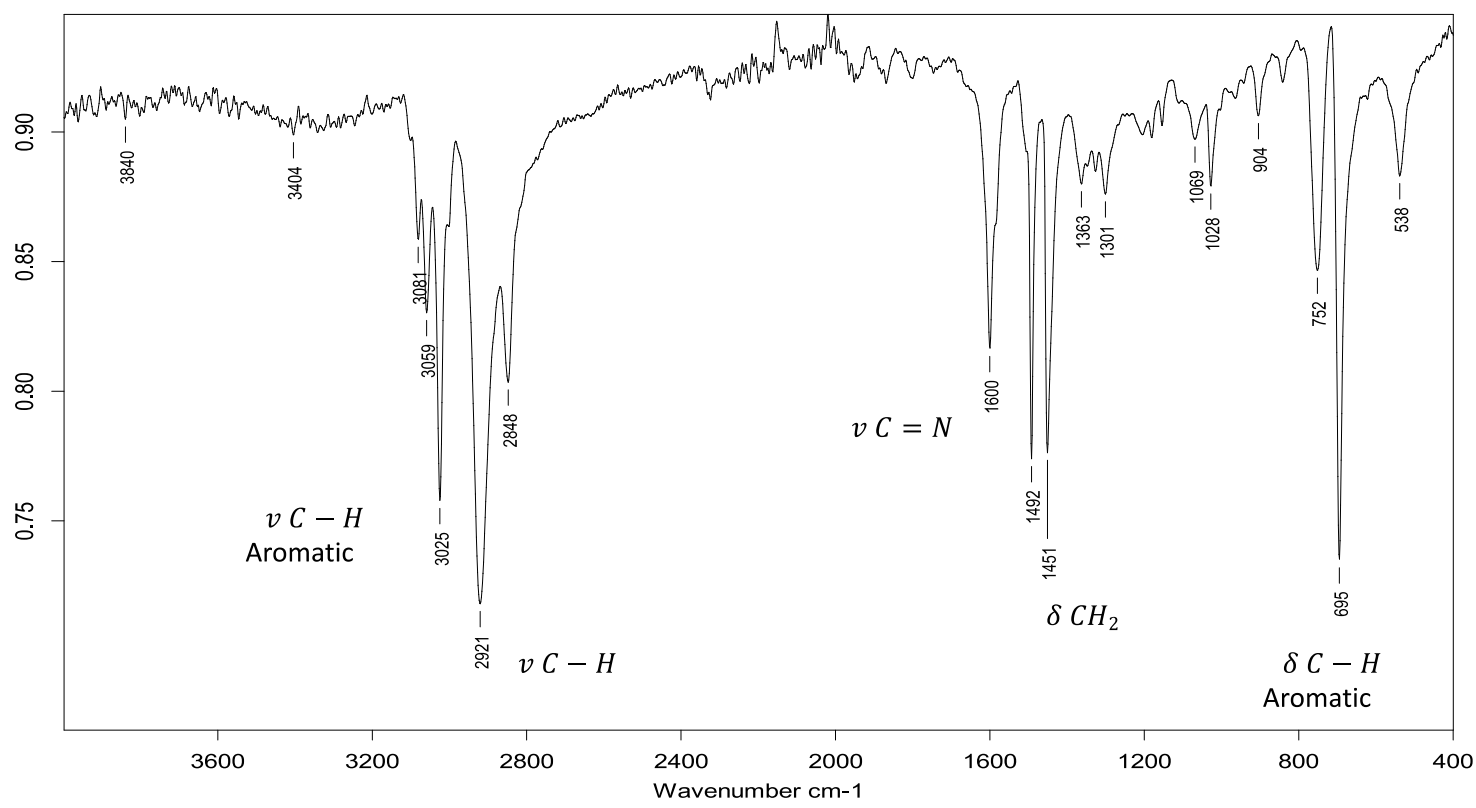

Figure S15: IR spectrum (neat) for TBD-2@ Merrifield (4). 


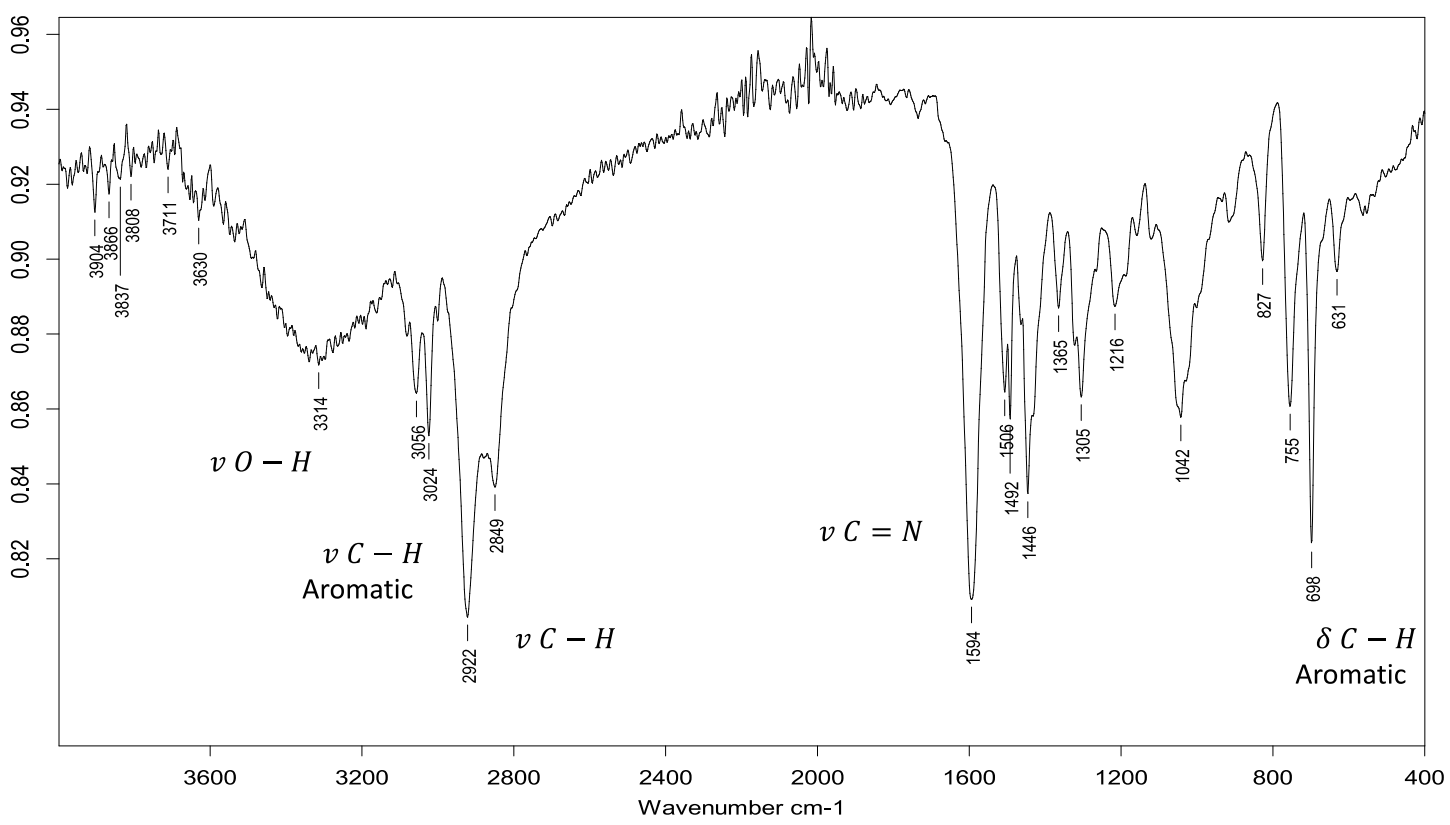

Figure S16: IR spectrum (neat) for TBD@Barlos (5). 